\title{
Modelling the Influence of Manufacturing Process Variables on Dimensional Changes of Porcelain Tiles
}

\author{
Dolly Santos-Barbosa, ${ }^{1,2}$ Dachamir Hotza, ${ }^{1}$ Juan Boix,${ }^{3}$ and Gustavo Mallol ${ }^{3}$ \\ ${ }^{1}$ Programa de Pós-Graduação em Ciência e Engenharia de Materiais (PGMAT), Universidade Federal de Santa Catarina (UFSC), \\ 88040-900 Florianópolis, SC, Brazil \\ ${ }^{2}$ Departamento de Ingeniería Química y Ambiental, Universidad Nacional de Colombia, 111321 Bogotá, Colombia \\ ${ }^{3}$ Instituto de Tecnología Cerámica (ITC), Asociación de Investigación de las Industrias Cerámicas, Universitat Jaume I, \\ 12006 Castellón, Spain \\ Correspondence should be addressed to Dachamir Hotza; dhotza@gmail.com
}

Received 24 February 2013; Revised 9 September 2013; Accepted 10 September 2013

Academic Editor: Augusto Deus

Copyright (C) 2013 Dolly Santos-Barbosa et al. This is an open access article distributed under the Creative Commons Attribution License, which permits unrestricted use, distribution, and reproduction in any medium, provided the original work is properly cited.

\begin{abstract}
A model to study the influence of main process variables (powder moisture, maximum compaction pressure, and maximum firing temperature) on the intermediate variables (mass, dry bulk density, size, and thickness) and the final dimensions of porcelain tiles is proposed. The properties of dried and fired bodies are basically determined by the process parameters when the physical, chemical, and mineralogical characteristics of the raw material are kept constant. For a given set of conditions, an equation could be sought for each property as a function of raw materials and processing. In order to find the relationship between moisture content and compaction pressure with dry bulk density, springback, and drying and firing shrinkage, a laboratory experimental design with three factors and four levels was applied. The methodology was validated in lab scale for a porcelain tile. The final size and thickness were estimated, and the influence of the main process variables was analysed.
\end{abstract}

\section{Introduction}

The integration of systems as a requisite to permit a multistage control in the ceramic industry has advanced in the last decades, but it is still behind the traditional chemical industry [1-3]. This is partly because the ceramic sector works with solids, and the level of knowledge in unit operations involving solids has progressed far less than in fluids [4]. The second point that makes automatic control difficult stems from the structural nature of the ceramic product, making the required end characteristics to be multiple and complex, unlike most of the chemical processes in which the most important feature is usually the chemical composition, as revised by Mallol [5]. In the case of ceramic tiles, the end product must meet a number of requirements that range from purely technical characteristics (low porosity and wear resistance) to aesthetic qualities (gloss and design), often restricting the implementation of control systems. Finally, another aspect that makes automation difficult in this type of industry is the wide variety of products that the same company usually needs to produce.
An implementation of techniques of control and automation in the ceramic tile industry would be justified for high value products, which must present a strict tolerance of properties, particularly regarding geometrical dimensions. Among the different types of ceramic tiles that are produced, as defined by the Spanish Ceramic Tile Manufacturers' Association [6], the porcelain tiles best meet these requirements. A porcelain tile is characterized by low water absorption, usually less than $0.5 \%$ for the BIa group [7], high mechanical strength and frost resistance, high hardness, and high chemical and stain resistance, with a broad spectrum of aesthetic possibilities (body colouring with soluble stains, pressed relief, polishing, glazing, etc.), according to a recent review [8].

The usual industrial wet-route processing of porcelain tile covers three main stages: (1) milling/mixing and spray drying of the raw materials, (2) pressing, drying, and decorating of the green body, and (3) firing and classifying of the finished product. The first stage starts with the homogenization and wet milling of raw materials, followed by spray-drying of 
the resulting suspension. In the second stage, the spraydried powder with moisture content between 0.05 and $0.07 \mathrm{~kg}$ water $/ \mathrm{kg}$ dry solids is pressed using uniaxial presses at a maximum pressure from 40 to $50 \mathrm{MPa}$. In the sequence, the resulting body is dried and decorated. Finally, in the third stage, the decorated body is fired in a single-layer roller kiln, using cycles of 40 to $60 \mathrm{~min}$ at a maximum temperature from 1180 to $1220^{\circ} \mathrm{C}$ for obtaining the maximum densification. After firing, the tiles are classified according to aesthetic properties and dimensional aspects, which are naturally related to processing and composition characteristics [9]. Some industries comprise in a single plant the Steps (1) to (3); other ones purchase the granulated powder from a third part processing unit, being restricted to Steps (2) and (3). The latest approach is followed in this paper.

One of the main concerns is related to the dimensional uniformity of the tile (size and form). In the case of size, the manufacturers generally divide the standard tolerance into different categories. The challenge of dimensional control is to produce the highest amount of tiles within a standardized specification to reduce storage lots.

The dimensional changes of ceramic tiles have been broadly studied in the last decades, using different approaches. The final size of fired bodies has been related to the composition of raw materials and/or processing parameters, including preparation, forming, and firing steps. Some of these works could be associated with tentative approaches to provide data for future-automated control of unit operations in the ceramic tile industry. Particularly, pressing and firing steps have been studied more deeply.

The characteristics of an industrial powder and the influence of its particle size distribution on the wet and fired densities were studied by Amorós et al. [10]. Extensive density and porosity measurements were carried out both in the green and the fired states. A proposal was made for the optimization of pressing conditions, including adjustment of pressure if the humidity changes [11]. Any excessive deviation from required dimensions of the fired product might be corrected by adjusting the green density and density distribution, with the help of experimentally determined dependence on moisture content and compacting pressure and on the basis of the relationship between green density and firing shrinkage [12]. Dimensional variations of only $0.1 \%$ are enough to cause significant deformations on large tiles. This fault was traced to nonuniform temperature in the preheating zone [13].

A system for effective control of pressing was proposed by Amorós et al. [14], based on modifying maximum pressing pressure to correct the variations in spray-dried powder moisture content, which needs to be measured on line in the pressed bodies. The validity of this method was verified, and it was shown that the maximum fluctuations of moisture content in typical tile manufacturing conditions sometimes exceed the admissible variation for this variable. De Noni Jr. et al. [15] applied a mathematical modelling to quantify the influence of process control variables on the length of fired tile manufactured from raw materials and processes, used by two floor-tile producers. Nevertheless, the influence of the main process variables (compaction pressure and powder moisture) on the final and intermediate characteristics of

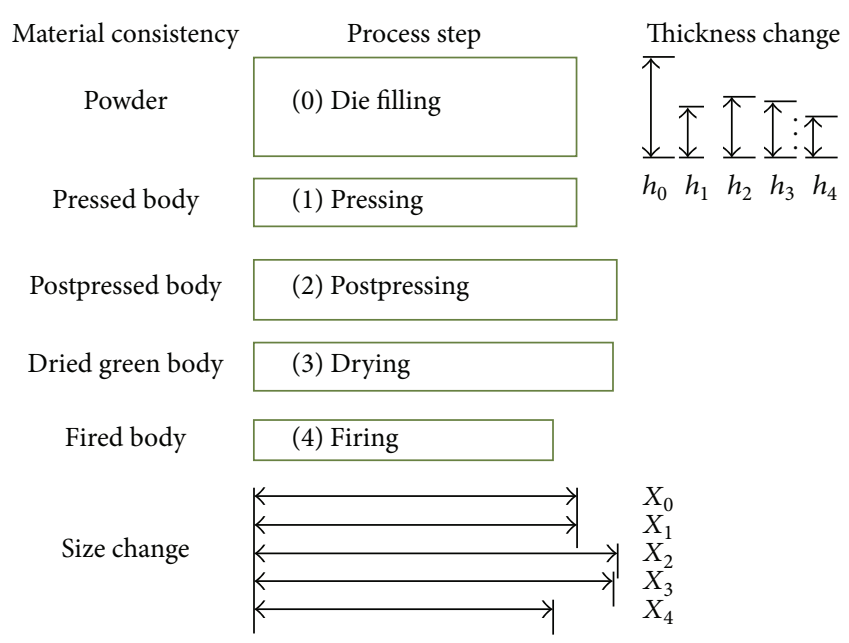

Figure 1: Dimensional changes through the process of porcelain tiles.

the tiles (mass, size, and thickness) was not yet accomplished in the literature considering the tile manufacturing process as a whole.

The scope of this work is developing empirical relationships to obtain a model for predicting the final dimensions of tiles (diameter and thickness) in lab scale, taking into account the dimensional changes experienced along the manufacturing steps.

\section{Ceramic Tile Manufacturing Process and Variables}

During the manufacturing process, ceramic tiles suffer from dimensional changes in different stages, as shown in Figure 1. Step 0 corresponds to die filling, in which the dimensions (thickness, $h$, and diameter or length, $X$ ) are related to the matrix volumes $\left(h_{0}\right.$ and $\left.X_{0}\right)$. In pressing, Step 1 , compaction occurs, the volume decreases, and the body dimensions correspond to $h_{1}$ and $X_{1}$, where $X_{1}=X_{0}$. After pressing, Step 2, an expansion-also known as springback - takes place. The thermal treatments-drying and sintering (Steps 3 and 4, resp.)-lead to shrinkages.

The dimensional changes experienced by tiles after pressing and drying (postpressing expansion and drying shrinkage, resp.) are determined for a given composition by pressing conditions (powder moisture and maximum compaction pressure, primarily), according to Amorós [16]. The dry bulk density of the tile (directly related to the maximum pressure and powder moisture) and the maximum firing temperature determine the dimensional changes experienced by the tile during firing (firing shrinkage), after studies of Escardino et al. [17]. An equation was obtained by Amorós et al. [18], which calculates the final size of the pieces from their dry bulk density and maximum firing temperature, taking into account the firing shrinkage.

Studies usually focus their attention on the largest of the tile dimensions, the length $(X)$, because it features one of the main properties of the final product's size. However, since the shrinkage occurs in three dimensions, the final thickness 


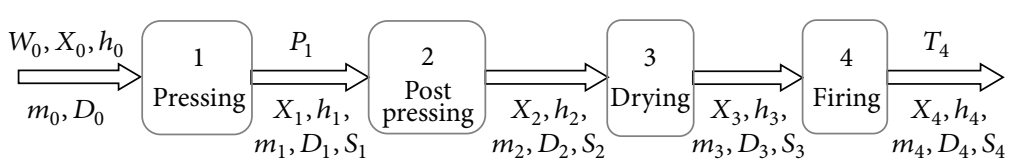

FIGURE 2: Flow diagram and variables of porcelain tile fabrication process.

of tiles $\left(h_{4}\right)$ is affected by the process variables as well. This parameter is conditioned not only by the dimensional changes experienced by the compacted tile during manufacture (Figure 1), but also by the initial thickness of the bed in the press $\left(h_{0}\right)$, that is, the spray-dried powder mass deposited in the press before compacting. Studies have shown the influence of the fill density of press powder beds, which will further affect the final thickness of the ceramic tile [19].

In Figure 2, different variables are shown, which will be taken into account to analyse the volume changes that were undertaken by the ceramic bodies along the processing steps, according to Figure 1.

In Figure 2, the processing variables are

$W_{0}$ : dry-basis spray-dried moisture content (\%),

$X$ : general characteristic size $(\mathrm{mm})$; in lab-scale it corresponds to diameter of a cylindrical sample and in industrial scale to width or length of rectangular tiles,

$h$ : thickness (mm),

$m$ : mass $(\mathrm{g})$,

$D:$ density $\left(\mathrm{kg} / \mathrm{m}^{3}\right)$,

$P_{1}$ : maximum compaction pressure $(\mathrm{MPa})$,

$S$ : linear dimensional change based on length or diameter (\%),

$T_{4}$ : maximum firing temperature $\left({ }^{\circ} \mathrm{C}\right)$.

The subscripts stand for the sequential number related to the respective unit operation. In this work, the variables over the arrow in Figure 2 correspond to independent ones, whose values are fixed, while the variables under the arrow are the dependent ones, whose values are estimated.

The sample dimensional changes, namely, springback, after pressing and shrinkage after drying and firing, were calculated in percentage as

$$
S_{i}=\frac{100\left(X_{i-1}-X_{i}\right)}{X_{i-1}},
$$

where the subscript corresponds to the stage number.

The lateral dimensions of the body associated with compaction pressing are considered unchanged since the powder compact is limited by the matrix physical boundaries. The springback effect corresponds to an expansion after removing the body from the press $\left(S_{2}\right.$ is negative). Following drying and firing, respective shrinkages occur $\left(S_{3}\right.$ and $S_{4}$ are positive). Applying (1) to the processing steps, the following equation is obtained:

$$
R_{4}=\left(100-S_{2}\right)\left(100-S_{3}\right)\left(100-S_{4}\right) 10^{-6} R_{1},
$$

where $R_{1}$ : length/diameter or thickness after pressing $(\mathrm{mm})$, $R_{4}$ : length/diameter or thickness after firing $(\mathrm{mm})$.

In this case, it is assumed that the expansion $\left(S_{2}\right)$ and shrinkages $\left(S_{3}\right.$ or $\left.S_{4}\right)$ are independent of the direction. Thus, the body final dimension $\left(R_{4}\right)$ may be obtained from the body dimensions after pressing (Step 1), when the values of $S_{2}, S_{3}$, and $S_{4}$ are known.

For a given composition, springback $\left(S_{2}\right)$ and drying shrinkage $\left(S_{3}\right)$ are basically dependent on powder moisture $\left(W_{0}\right)$ and maximum compaction pressure $\left(P_{1}\right)$. Firing shrinkage $\left(S_{4}\right)$ is mainly a function of dry bulk density $\left(D_{3}\right)$ and maximum firing temperature $\left(T_{4}\right)$, and $D_{3}$ depends on $W_{0}$ and $P_{1}$. These relationships might be obtained empirically for each composition as follows:

$$
\begin{aligned}
& S_{2}=f\left(W_{0}, P_{1}\right), \\
& S_{3}=f\left(W_{0}, P_{1}\right), \\
& S_{4}=f\left(D_{3}, T_{4}\right), \\
& D_{3}=f\left(W_{0}, P_{1}\right) .
\end{aligned}
$$

Thus, $S_{2}, S_{3}, S_{4}$, and $D_{3}$ may be calculated for a certain composition from the independent variables $W_{0}, P_{1}$, and $T_{4}$, using (3) to (6).

Considering that after pressing and before mould extraction the body length or diameter $\left(X_{1}\right)$ is the same mould dimension $\left(X_{0}\right)$, the equation to calculate the characteristic size of the body after firing $\left(X_{4}\right)$ may be written as

$$
X_{4}=\left(100-S_{2}\right)\left(100-S_{3}\right)\left(100-S_{4}\right) 10^{-6} X_{0} \text {. }
$$

Equations (7) and from (3) to (6) allow estimating the final size of bodies as a function of independent variables $W_{0}$, $P_{1}, T_{4}$, and $X_{0}$. Similarly, to calculate the body thickness after firing $\left(h_{4}\right),(2)$ may be rewritten as

$$
h_{4}=\left(100-S_{2}\right)\left(100-S_{3}\right)\left(100-S_{4}\right) 10^{-6} h_{1} .
$$

Equation (8) is not directly applied, since the thickness after pressing $\left(h_{1}\right)$ is not the same thickness of the powder bed $\left(h_{0}\right)$, which is the independent variable. To calculate $h_{1}$, it is assumed that the body mass $(m)$ is changed only during drying (9), so that the density definition after each $i$ step is considered (10), where $A_{i}$ is the body area $\left(\mathrm{m}^{2}\right)$ after Step $i$. Consider

$$
\begin{gathered}
m_{0}=m_{1}=m_{2}, \\
D_{i}=\frac{m_{i}}{h_{i} A_{i}} .
\end{gathered}
$$




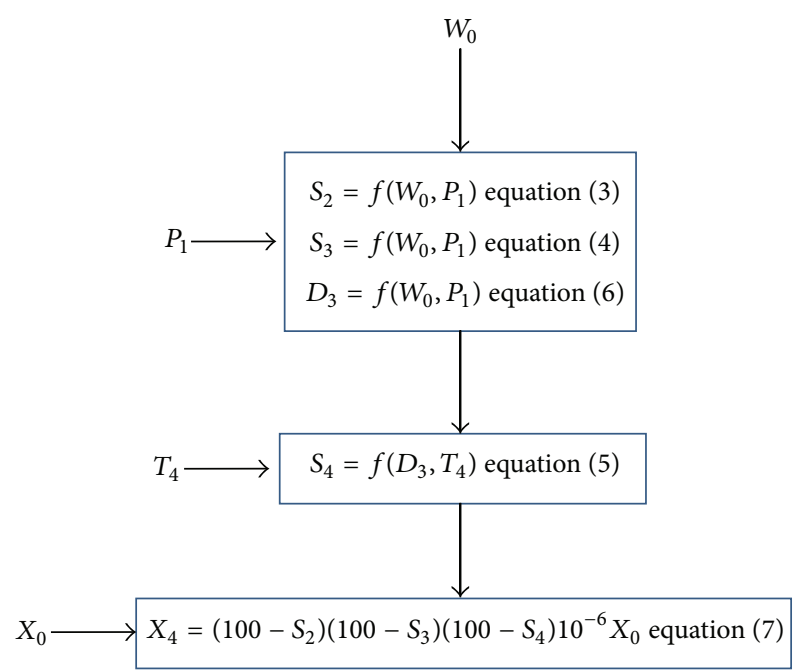

(a)

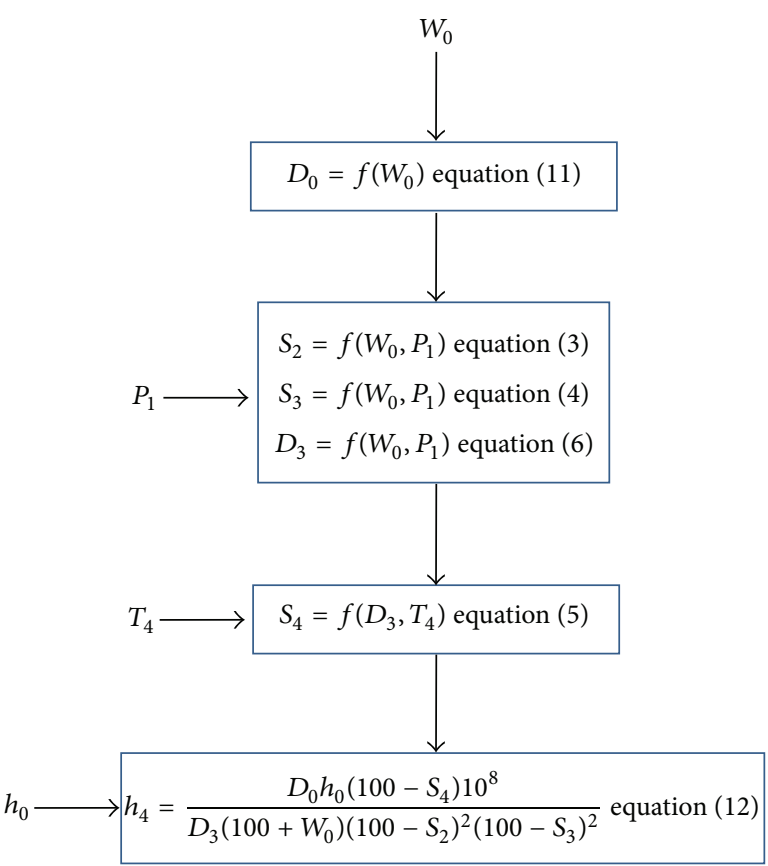

(b)

FIGURE 3: Flow charts for calculating the dimensional changes of ceramic tiles: (a) final length or diameter $\left(X_{4}\right)$ and (b) final thickness $\left(h_{4}\right)$.

The fill density, $D_{0}$, is fundamentally affected by the way the powder is prepared, since the preprocessing steps define the particle or granule size distribution as well as their shape and moisture content. For spray-dried powders, whose size and shape are maintained relatively constant, $D_{0}$ depends solely on the moisture content (11). This equation is also empirically obtained for a specific powder bed. Consider

$$
D_{0}=f\left(W_{0}\right) .
$$

After previous assumptions, (8) might be redefined as

$$
h_{4}=\frac{h_{0} D_{0}\left(100-S_{4}\right) 10^{8}}{D_{3}\left(100+W_{0}\right)\left(100-S_{2}\right)^{2}\left(100-S_{3}\right)^{2}},
$$

where $\left(h_{4}\right)$ : final thickness. From (12), the final body thickness may be calculated directly from independent variables $\left(h_{0}\right.$ and $\left.W_{0}\right)$ and from dependent variables $\left(S_{2}, S_{3}, S_{4}, D_{0}\right.$, and $D_{3}$ ), which by their turn may be obtained from (3) to (6) and (11).

Figure 3 presents flow charts, indicating the sequential steps to calculate the dimensional changes of ceramic tiles $\left(X_{4}\right.$ and $\left.h_{4}\right)$ from independent variables $\left(X_{0}, h_{0}, W_{0}, P_{1}\right.$, and $\left.T_{4}\right)$, and from (3) to (7), (11), and (12).

As stated before, the scope of this work is developing empirical relationships for $S_{2}, S_{3}, S_{4}, D_{0}$, and $D_{3}$ to obtain a model for predicting the final dimensions of tiles (diameter and thickness) in lab scale, taking into account the dimensional changes experienced along the manufacturing steps. Furthermore, the influence of the main process variables (compaction pressure and powder moisture) on the final and intermediate characteristics of the tiles (mass, size, and thickness) will be also accomplished.

\begin{tabular}{|c|c|}
\hline Chemical compound & Mass (\%) \\
\hline $\mathrm{SiO}_{2}$ & 65.8 \\
\hline $\mathrm{Al}_{2} \mathrm{O}_{3}$ & 20.6 \\
\hline $\mathrm{Fe}_{2} \mathrm{O}_{3}$ & 0.66 \\
\hline $\mathrm{CaO}$ & 0.66 \\
\hline $\mathrm{MgO}$ & 1.34 \\
\hline $\mathrm{Na}_{2} \mathrm{O}$ & 4.48 \\
\hline $\mathrm{K}_{2} \mathrm{O}$ & 1.60 \\
\hline $\mathrm{MnO}$ & $<0.01$ \\
\hline $\mathrm{P}_{2} \mathrm{O}_{5}$ & 0.09 \\
\hline Loss on fire at $1025^{\circ} \mathrm{C}$ & 3.91 \\
\hline
\end{tabular}

TABLE 1: Chemical analysis of spray-dried powder.

\section{Materials and Methods}

3.1. Raw Materials. A spray-dried powder with standard porcelain tile composition was used. The particle size distribution is represented in Figure 4. The larger fraction $(\sim 60 \%)$ corresponds to particles between 300 and $500 \mu \mathrm{m}$, as usually employed in the porcelain tile industry.

The chemical analysis and X-ray diffraction pattern of the studied ceramic powder are shown in Table 1 and Figure 5, respectively. The main crystalline phases were identified. From the mineralogical and chemical analysis of the samples, a rational analysis was carried out, according to the method developed by Coelho et al. [20]. The percentages of crystalline phases so obtained are presented in Table 2.

3.2. Experimental Design. Experiments were performed in order to find the regression equations, relating the fill density $\left(D_{0}\right)$, dry bulk density $\left(D_{3}\right)$, springback $\left(S_{2}\right)$, and drying 
TABLE 2: Rational mineralogical analysis of spray-dried powder.

\begin{tabular}{lc}
\hline Crystalline phase & Mass (\%) \\
\hline Albite & 38 \\
Quartz & 24 \\
Kaolinite & 18 \\
Muscovite/illite & 14 \\
Chlorite & 5 \\
Other & 1 \\
\hline
\end{tabular}

TABLE 3: Factor levels of processing parameters: powder moisture $\left(W_{0}\right)$, compaction pressure $\left(P_{1}\right)$, and firing temperature $\left(T_{4}\right)$.

\begin{tabular}{lcccc}
\hline Factors & \multicolumn{4}{c}{ Levels } \\
& 1 & 2 & 3 & 4 \\
\hline$W_{0}(\%)$ & 3.11 & 4.59 & 5.67 & 7.18 \\
$P_{1}(\mathrm{MPa})$ & 16.61 & 29.42 & 39.23 & 49.03 \\
$T_{4}\left({ }^{\circ} \mathrm{C}\right)$ & 1150 & 1176 & 1200 & 1220 \\
\hline
\end{tabular}

and firing shrinkage $\left(S_{3}\right.$ and $\left.S_{4}\right)$ of porcelain tiles to the independent variables-powder moisture $\left(W_{0}\right)$, compaction pressure $\left(P_{1}\right)$, and firing temperature $\left(T_{4}\right)$ - under constant raw material characteristics. In other words, the aim is to define the functions of (3) to (6) and (12).

An experimental design with 4 levels was initially used to characterize the nonlinear relationship among variables, as shown in Table 3. For each thermal treatment, a combination of pressure and moisture content was applied, and three cylindrical test bodies were pressed.

Since three factors $\left(W_{0}, P_{1}\right.$, and $\left.T_{4}\right)$ and four levels were chosen, a complete experimental design would require 64 experiments without replicates. Considering that the output variables $D_{0}, D_{3}, S_{2}$, and $S_{3}$ are related to $W_{0}$ and $P_{1}$ but not to $T_{4}$, a reduced experimental set comprising two factors and four levels was applied.

Test bodies were simultaneously used to find the relation between $S_{4}$ and the output variables $D_{3}$ and $T_{4}$. After drying, all samples were reorganized in four groups, one for each level of temperature. A selection was done, so that each group contained pieces within all ranges of dry bulk density.

3.3. Processing. The processing methodology used closely follows the conventional porcelain tile industrial practice, from pressing to firing stages. However, since the decorating stage is not significant to the dimensional changes, it was not included.

The industrial standard powder was separated into four bags. Each one had the moisture content, adjusted by adding water or drying in a muffle oven. For each $W_{0}$ and $P_{1}$, shown in Table 3, three cylindrical specimens $(40 \times 7 \mathrm{~mm})$ were formed by uniaxial pressing in a hydraulic laboratory press with electronic pressure control (Nannetti), using about $20 \mathrm{~g}$ of material for each specimen. Right after body pressing, the sample was weighted, marked, and carefully placed into a bag for $30 \mathrm{~min}$. Then, the diameter, thickness, and bulk density were measured.

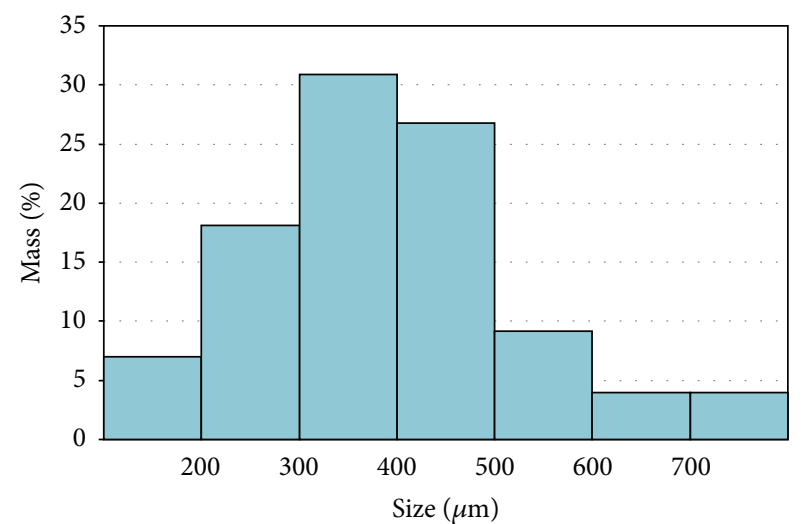

FIGURE 4: Granule size distribution for spray-dried powder.

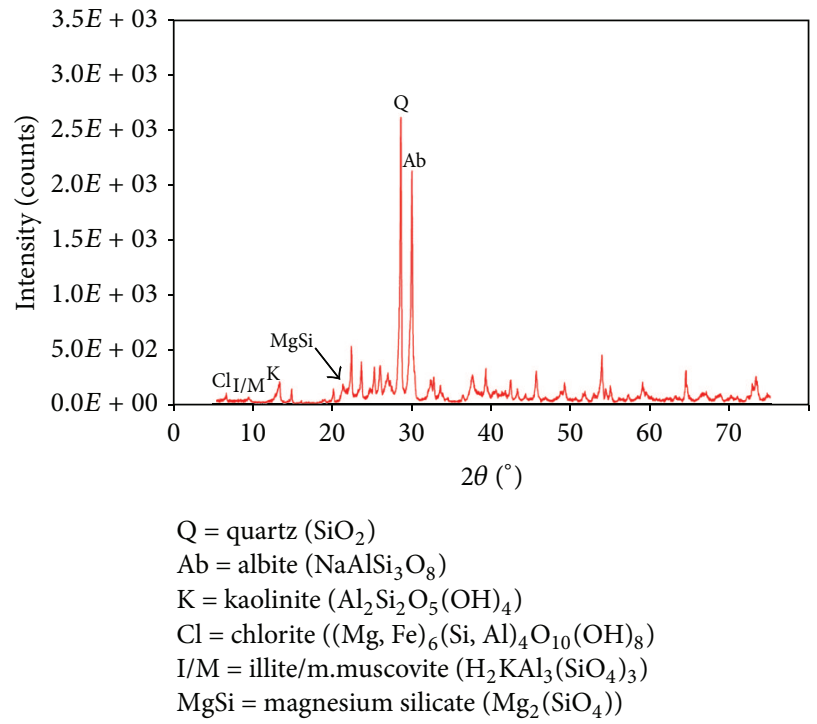

FIGURE 5: X-ray diffraction pattern for spray-dried powder.

After compaction, the test pieces were oven dried at $110 \pm 5^{\circ} \mathrm{C}$ until reaching a constant mass. The moisture content of the bodies was calculated as a difference of mass before and after drying. Afterwards, they were fired in a laboratory electrical kiln (Pirometrol, maximum operating temperature range $1250^{\circ} \mathrm{C}$ ), using heating cycles similar to the industrial practice (fast heating to $500^{\circ} \mathrm{C}$ and at $25^{\circ} \mathrm{C} / \mathrm{min}$ from $500^{\circ} \mathrm{C}$ until reaching the maximum temperatures, shown in Table 3). The pieces were kept to the maximum temperature during $6 \mathrm{~min}$. Afterwards, they were cooled with forced air using a fan. The mass, dimensions, and bulk density of the dried and fired samples were measured. The water absorption of the fired bodies was measured additionally. The apparent densities $\left(D_{2}, D_{3}\right.$, and $\left.D_{4}\right)$ of the bodies were measured by the Archimedes immersion method.

The linear shrinkage was calculated from the change in diameter (measured with $0.02 \mathrm{~mm}$ resolution digital calliper) of the cylindrical test pieces. Water absorption was determined after immersion in boiling water for $2 \mathrm{~h}$ and using a digital analytical scale with a resolution of $0.03 \mathrm{~g}$. The mass of the tiles was measured both before and after immersion to determine the percentage of water absorption. 
For determining fill density, the industrial standard powder was adjusted to the selected highest water content by moisturizing. The graduated cylinder was filled by pouring the powder, and the fill density was calculated as the ratio of mass to the cylinder volume. Then, the moisture content was reduced by natural drying. For each value of moisture content, the weighing was made three times with different powders to calculate the experimental error.

3.4. Modelling and Analysis. When the physical, chemical, and mineralogical characteristics of the raw material are kept constant, the properties of dried and fired bodies are basically determined by the process conditions. For a given set of raw materials and processing conditions, an equation could be sought for each property, relating that property with such conditions.

Equations for estimating $D_{3}$ and $S_{4}$ are found in the literature $[16,18]$. For the remaining variables, new equations were proposed. After analysing different regressions (polynomial, exponential, and logarithmical), the equation which provided the lowest standard deviation of the residuals was chosen, provided that the expected physical behaviour was adequately described.

For each $W_{0}$ and $P_{1}$, the response values used in the experimental design represent the average of three measured values, respectively. A regression was fitted to the experimental values, and the regression adequacy was checked. The assumption of normal distribution was proved when the residuals were uncorrelated and randomly distributed with a zero mean value [21]. In most cases, it was known that there was a relation among the three variables.

The regression uncertainty at 95\% confidence level was calculated based on a global experimental error. If it is considered that the experimental error is the same throughout the whole region of interest [22], a weighted average (estimate of the standard deviation of the population) can be calculated based on the local experimental errors and the corresponding degrees of freedom. The value of the variable will be equal to the value predicted by the regression plus or minus the half of the $95 \%$ confidence interval $\left(\mathrm{CI}_{95 \%}\right)$, calculated as

$$
\mathrm{CI}_{95 \%}=\frac{2 t s_{G}}{\sqrt{n}},
$$

where $s_{G}$ is the global (or weighted average) experimental error, $n$ is the sample size, and $t$ is the $t$ distribution value as a function of the chosen level of confidence (95\%) and the degrees of freedom. The significant digits of the coefficients were adjusted following an error analysis.

\section{Results and Discussion}

This section is structured in two parts. In the first one, (3) to (6) and (11) are presented, which characterize the behaviour of the studied composition in each manufacturing step where dimensional changes occur. In the second one, those equations are used to predict the final diameter $\left(X_{4}\right)$ and thickness $\left(h_{4}\right)$ in lab scale and to analyse the influence of main process variables (powder moisture $\left(W_{0}\right)$ and maximum compaction

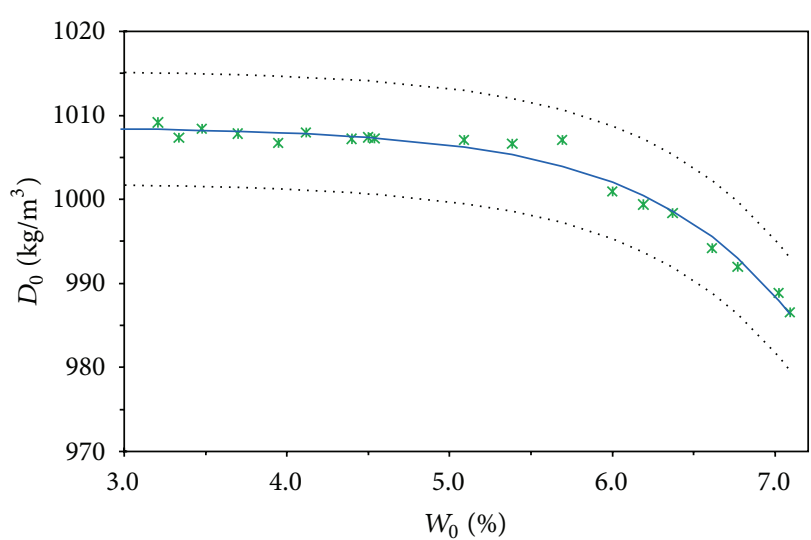

FIGURE 6: Fill density $\left(D_{0}\right)$ as a function of the powder moisture content $\left(W_{0}\right)$ with $\mathrm{CI}_{95 \%}$.

pressure $\left(P_{1}\right)$ ) on the intermediate variables (mass, size, and thickness) and the final dimensions of ceramic tiles.

4.1. Equations in Lab Scale. Measured values for $D_{0}, S_{2}, D_{3}$, and $S_{4}$ were obtained at the different levels of the three factors $W_{0}, P_{1}$, and $T_{4}$, shown in Table 3 . The regression equations from (3) to (6) and (11), were fitted with these values, and confidence intervals $\left(\mathrm{CI}_{95 \%}\right)$ were calculated. The final results are analysed as follows.

4.1.1. Die Filling. The way how the moisture content, $W_{0}$, affects the fill density, $D_{0}$, (11) is presented in Figure 6. Experimental values of $D_{0}$ were correlated to $W_{0}$ by the following exponential equation:

$$
D_{0}=B+C \exp \left(E W_{0}\right)
$$

where $B, C$, and $E$ are adjusting experimental parameters.

Equation (15) represents the regression obtained for the particular composition of porcelain tile used in this work with a correlation coefficient, $R^{2}$, of 0.9887 . Consider

$$
D_{0}=1008.6-8.1000 \times 10^{-3} \exp \left(1.1171 W_{0}\right) .
$$

The estimation of the fill density corresponding to the $95 \%$ confidence level is defined by (16). In Figure 6, the upper and lower limits of the curves that correspond to the $95 \%$ confidence for the regression are presented as well. Consider

$$
\left.D_{0}\right|_{95 \%}=\frac{D_{0} \pm \mathrm{CI}_{95 \%}}{2}=D_{0} \pm 7 \mathrm{~kg} / \mathrm{m}^{3} .
$$

The experimental data are well adjusted by (15). Moreover, the constant $B$ corresponds to the fill density, so that when $W_{0}=0, D_{0} \approx B$. From Figure 6, the density decreases as the moisture increases, which is more noticeable for moisture contents $>5 \%$. In practice, the mould volume is constant, so that a moisture increase is related to a decrease in the dry powder feed to the mould, especially for $W_{0}>5 \%$, which is the usual working range for this kind of ceramic tiles. According to Reed [23], the fill density depends directly on the granule density and the packing behaviour. 


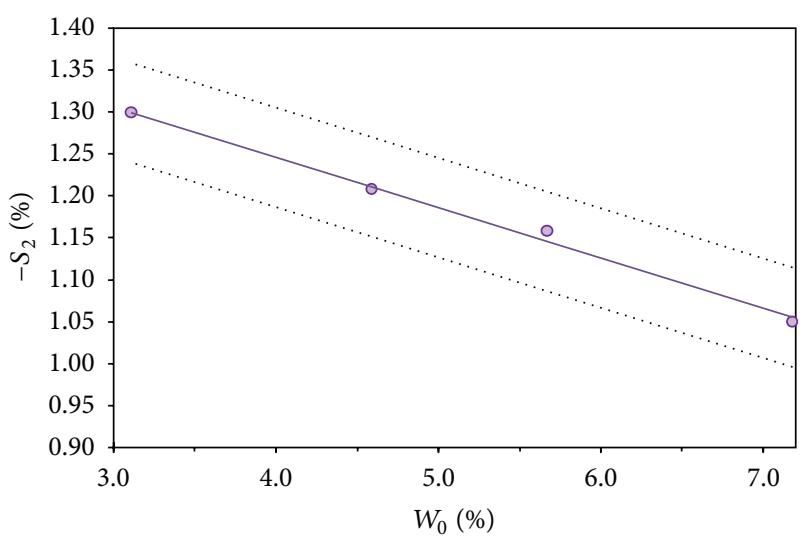

FIGURE 7: Springback $\left(S_{2}\right)$ as a function of the powder moisture content $\left(W_{0}\right)$ at compaction pressure $\left(P_{1}\right)$ of $49.03 \mathrm{MPa}$ with $\mathrm{CI}_{95 \%}$ (dotted lines).

4.1.2. Pressing. In this section, the adjusted equations corresponding to springback $\left(S_{2}=f\left(P_{1}, W_{0}\right)\right)$ and compaction diagram $\left(D_{3}=f\left(P_{1}, W_{0}\right)\right)$ are included. Although $D_{3}$ is the dry bulk density of the green and dried body, that is, after drying, the depending variables in this case are $P_{1}$ and $W_{0}$, that is, pressing-related variables. The pressing stage mainly determines $D_{3}$, so that drying operating parameters (time and temperature) have minor influence [24].

Elastic energy stored in the compacted powder produces an increase in the dimensions of the pressed tile on an ejection, called springback $\left(S_{2}\right)$, which may cause compact defects on ejection when in excess. The springback experimental values for the porcelain tile powder used in this study are presented in Table 4 and Figure 7, in which, for convenience, $-S_{2}$ was used. Those values were measured, considering the difference between the tile size after being taken out from the mould and the pressing matrix constant dimensions.

It is observed from Table 4 that, as expected, the springback $\left(-S_{2}\right)$ increases when $P_{1}$ is raised and $W_{0}$ is reduced. The results are consistent with the literature; for the same compaction pressure, $-S_{2}$ decreases when $W_{0}$ is increased up to a level of $9 \%$ due to the influence of the moisture over the mechanical properties of the spray-dryer granules [16]. It is expected that $-S_{2}$ rises with increasing values of $P_{1}$, but this effect is less pronounced at higher $W_{0}$.

A linear relationship between $-S_{2}$ and $W_{0}$ can be established, and changes of $P_{1}$ affect the intercept and slope of this regression. An adequate correlation of the three variables (17) was found corresponding to a residual standard deviation of $0.017 \%$. Consider

$$
\begin{aligned}
-S_{2}= & \left(-3.999 \times 10^{-4} P_{1}-0.04025\right) W_{0} \\
& +4.926 \times 10^{-3} P_{1}+1.244 .
\end{aligned}
$$

With a global experimental error of $0.023 \%$, the estimation of the springback with a $95 \%$ confidence level will be defined by

$$
-\left.S_{2}\right|_{95 \%}=\frac{-S_{2} \pm \mathrm{CI}_{95 \%}}{2}=-S_{2} \pm 0.06 \% .
$$

TABLE 4: Experimental values of springback $\left(S_{2}\right)$ as a function of the powder moisture content $\left(W_{0}\right)$ and compaction pressure $\left(P_{1}\right)$ with the data interval error at $95 \%$ confidence level.

\begin{tabular}{ccccc}
\hline \multirow{2}{*}{$-S_{2}(\%)$} & \multicolumn{5}{c}{$W_{0}(\%)$} \\
& 3.11 & 4.59 & 5.67 & 7.18 \\
\hline$P_{1}(\mathrm{MPa})$ & & & & \\
19.61 & $1.21 \pm 0.05$ & $1.08 \pm 0.04$ & $1.07 \pm 0.01$ & $1.00 \pm 0.02$ \\
29.42 & $1.23 \pm 0.09$ & $1.14 \pm 0.04$ & $1.10 \pm 0.01$ & $1.02 \pm 0.06$ \\
39.23 & $1.27 \pm 0.02$ & $1.14 \pm 0.09$ & $1.14 \pm 0.13$ & $1.03 \pm 0.06$ \\
49.03 & $1.29 \pm 0.01$ & $1.21 \pm 0.04$ & $1.16 \pm 0.04$ & $1.05 \pm 0.02$ \\
\hline
\end{tabular}

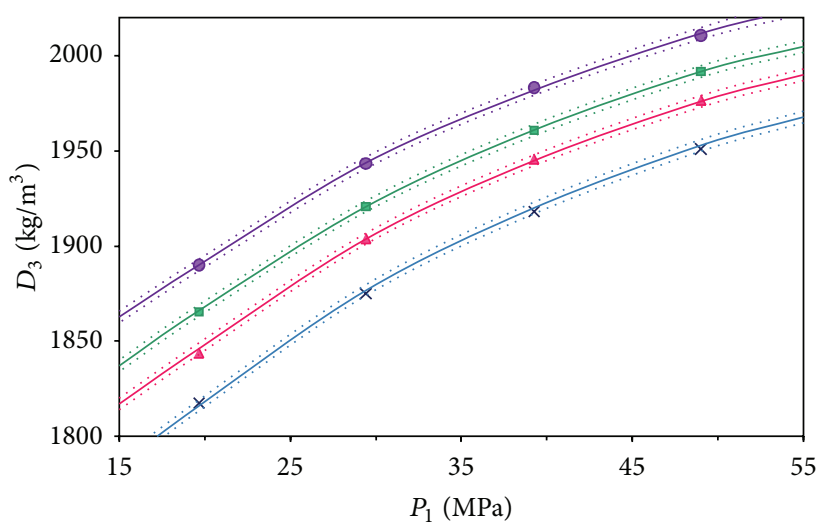

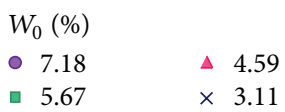

Figure 8: Dry bulk density $\left(D_{3}\right)$ as a function of the compaction pressure $\left(P_{1}\right)$ and powder moisture content $\left(W_{0}\right)$ with $\mathrm{CI}_{95 \%}$ (dotted lines).

For easy visualization, the relationship between $S_{2}$ and $W_{0}$ is shown only at one compaction pressure (for $49.03 \mathrm{MPa}$ ) in Figure 7. Upper and lower limits of the curves that correspond to the $95 \%$ confidence for the regression at 49.03 MPa are presented as well. Similar curves might be built for remaining pressures from Table 4 and (17) and (18).

4.1.3. Compaction Diagram. For a fixed composition, $D_{3}$ depends on $P_{1}$ and $W_{0}$, according to a relation known as compaction diagram [25], which might be expressed as

$$
D_{3}=Q W_{0}^{q} \ln P_{1}+R W_{0}^{r},
$$

where $Q, q, R$, and $r$ are empirical constants dependent on powder composition. The experimental data and the respective regression curves are shown in Figure 8.

The results show a significant influence of $W_{0}$ on $D_{3}$. To analytically express the influence of $P_{1}$ on $D_{3}$, the following equation was fitted. Consider

$$
D_{3}=174.85 W_{0}^{-0.1324} \ln P_{1}+1219.2 W_{0}^{0.10188} .
$$


Equation (21) is used to estimate $D_{3}$ within a $95 \%$ confidence level. The curves corresponding to a $\mathrm{CI}_{95 \%}$ for each $P_{1}$ are also shown in Figure 8. Consider

$$
\left.D_{3}\right|_{95 \%}=\frac{D_{3} \pm \mathrm{CI}_{95 \%}}{2}=D_{3} \pm 3 \mathrm{~kg} / \mathrm{m}^{3} \text {. }
$$

The residuals of the correlation shown in (20) have a mean of $-0.39 \mathrm{~kg} / \mathrm{m}^{3}$ and a standard deviation of $0.19 \mathrm{~kg} / \mathrm{m}^{3}$, values that validate the normality hypothesis.

4.1.4. Drying. Linear drying shrinkage $\left(S_{3}\right)$ occurs, as the liquid between the particles is removed and the interparticle separation decreases, and a linear correlation between $S_{3}$ and $W_{0}$ might be expected [16]. Shrinkage significantly increases when $W_{0}$ is raised and slightly decreases when the pressure is increased.

The maximum experimental mean value of $S_{3}$ was $0.04 \%$, while the standard deviation ranged between $0.01 \%$ and $0.07 \%$, resulting in large residual standard deviation (RSD) values, varying between 35 and $1054 \%$. On this basis, the experimental error was considered relatively high.

Additionally, by comparing the orders of magnitude of $S_{2}$, $S_{3}$, and $S_{4}$, it is concluded that the contribution of $S_{3}$ to the dimensional change is not significant. This result is consistent with the literature data that reports a volume shrinkage in the range of 3-12\% for extruded and slip cast parts but 0 for drypressed and injection-moulded parts [23].

4.1.5. Firing. As shown in Figures 9 and 10, for constant $D_{3}$, when $T_{4}$ is increased, the linear firing shrinkage $\left(S_{4}\right)$ reaches a maximum value and then decreases. The maximum value is reached at a higher temperature as $D_{3}$ decreases. The same tendency was observed elsewhere $[17,26]$, owing to the sintering mechanism of porcelain tiles, which includes the decomposition of some clay components generating gases inside the samples causing swelling. After a certain extent, $S_{4}$ decreases during sintering, since the gases are released [27, 28]. Likewise, for the same $T_{4}, S_{4}$ increases proportionally to $D_{3}$, that is, according to the initial porosity. Although only six curves are present in Figure 9, eleven different dry densities were taken into account to adjust the equation.

Porcelain tiles are required to have water absorption values lower than $0.5 \%$ [7] as well as to keep the dimensional changes with temperature within a specific range, so that a compromise must be found combining those two properties according to $T_{4}$ and $D_{3}$. Lower absorption values are obtained at higher values of $T_{4}$ and $D_{3}$.

An adequate correlation of the variables $S_{4}, T_{4}$, and $D_{3}$ was found with a residual standard deviation of $0.07 \%$ and a residual mean of nearly zero $(-0.02 \%)$. The mathematical regression and the corresponding graphical representation are shown in (22) and Figure 9, respectively. Threedimensional response surface showing the expected $S_{4}$ as a function of $T_{4}$ and $D_{3}$ is presented in Figure 10. Consider

$$
\begin{aligned}
S_{4}= & \left(3.9389 \times 10^{-7} T_{4}^{2}-1.07704 \times 10^{-7} T_{4}+0.70975\right) D_{3} \\
& -1.44726 \times 10^{-3} T_{4}^{2}+3.711346 T_{4}-2334.5
\end{aligned}
$$

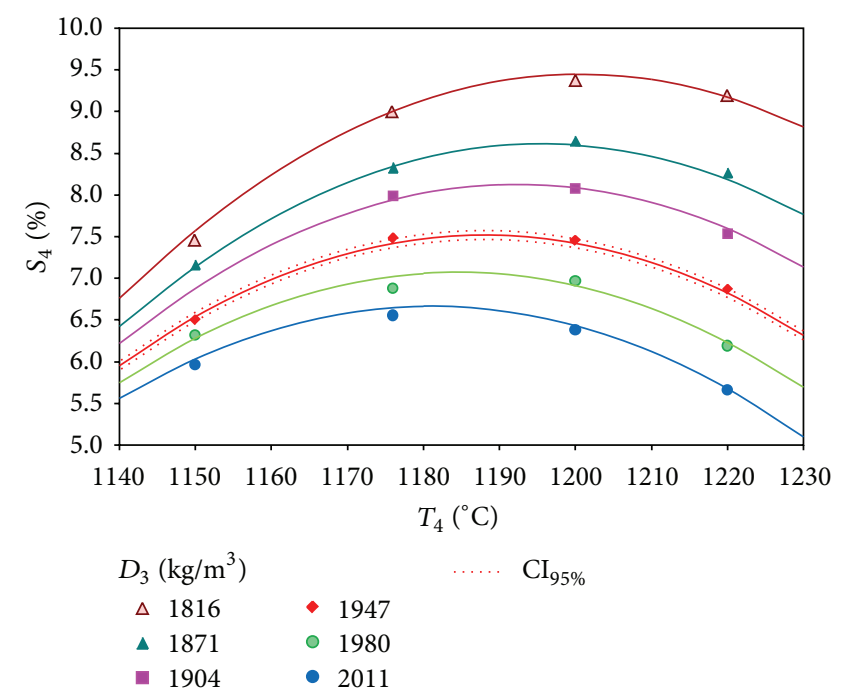

FIGURE 9: Linear firing shrinkage $\left(S_{4}\right)$ as a function of the maximum firing temperature $\left(T_{4}\right)$ and dry bulk density $\left(D_{3}\right)$.

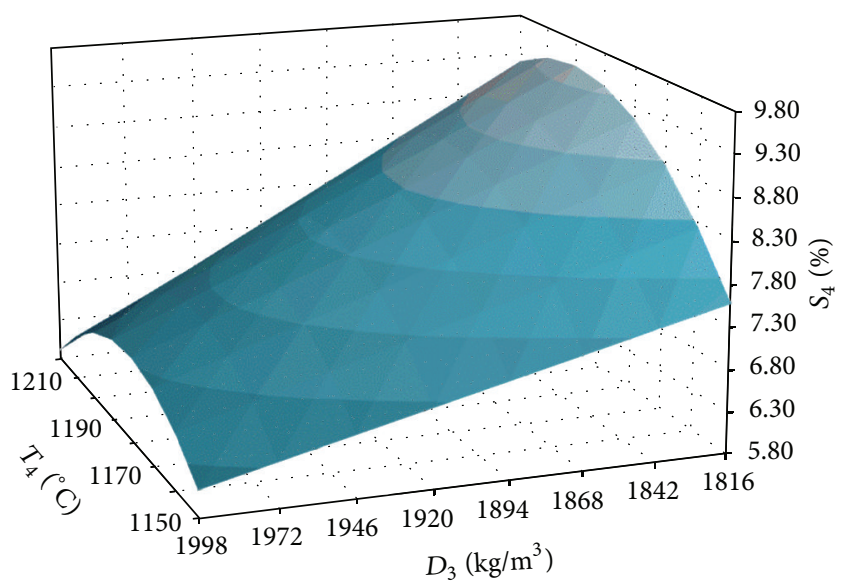

FIGURE 10: Three-dimensional response surface: linear firing shrinkage $\left(S_{4}\right)$ as a function of the maximum firing temperature $\left(T_{4}\right)$ and dry bulk density $\left(D_{3}\right)$.

According to the regression and for a dry bulk density of $1947 \mathrm{~kg} / \mathrm{m}^{3}$, a confidence interval of $0.20 \%$ was found with a weighted average experimental error of $0.042 \%$. The curves corresponding to the upper and lower limits of the confidence interval (for $D_{3}=1947 \mathrm{~kg} / \mathrm{m}^{3}$ ) are shown in Figure 9 .

\subsection{Estimation of Tile Dimensions in Lab Scale and Behaviour} Analysis of Intermediate Variables. In this section, the influence of main process variables $\left(W_{0}\right.$ and $\left.P_{1}\right)$ on the intermediate variables (mass, size, and thickness) and on the final dimensions of ceramic tiles was analysed following the study of the model adequacy to estimate the final dimensions $\left(h_{4}\right.$ and $X_{4}$ ) of ceramic tiles in lab scale.

4.2.1. Estimation of Tile Dimensions in Lab Scale. Using the proposed equations (Section 4.1) and following the scheme presented in Figure 3, the final piece dimension $\left(h_{4}\right.$ and $\left.X_{4}\right)$ was estimated. Those values were calculated for each one 
TABle 5: Experimental and estimate errors in final diameter and thickness estimation.

\begin{tabular}{lcccc}
\hline & $\begin{array}{c}\text { Residuals mean } \\
(\mathrm{mm})\end{array}$ & $\begin{array}{c}\text { Residuals standard deviation } \\
(\mathrm{mm})\end{array}$ & $\begin{array}{c}\text { Experimental absolute error } \\
(\mathrm{mm})\end{array}$ & $\begin{array}{c}\text { Mean absolute error } \\
(\mathrm{mm})\end{array}$ \\
\hline$X_{4}$ & 0.01 & 0.04 & 0.02 & 0.03 \\
$h_{4}$ & 0.00 & 0.18 & 0.50 & 0.14 \\
\hline
\end{tabular}

of the operational conditions $\left(W_{0}, P_{1}\right.$, and $T_{4}$, presented in Table 3) and the matrix dimensions $\left(h_{0}=14.27 \mathrm{~mm}\right.$ and $\left.X_{0}=40.01 \mathrm{~mm}\right)$. The estimated values were compared with measured values. To validate the assumption of normality, the residues were uncorrelated and randomly distributed with a standard deviation and mean value slightly over zero, as presented in Table 5. To validate the methodology, the average of the absolute value of the residuals (the mean absolute error, MAE) was also calculated and compared with the experimental absolute error (EAE). Their values are also presented in Table 5. EAE was calculated as an error associated with the half of the confidence interval with the same probability used through this work (0.95).

The regression can be considered adequate if the mean absolute error is smaller than the experimental absolute error. That is the case for $h_{4}$. Although the MAE, for $X_{4}$, is larger than EAE, its values are close.

4.2.2. Behaviour Analysis of Intermediate Variables. The influence of $P_{1}$ and $W_{0}$ on the mass, size, and thickness of the porcelain tile through the manufacturing process was studied following the methodology proposed with the previous equations (Section 4.1). For calculations, the values of $h_{0}$ and $X_{0}$ were assumed to be typical lab-scale values $(15 \mathrm{~mm}$ and $40 \mathrm{~mm}$, resp.).

(1) Influence of Powder Moisture on Tile Mass. According to (14), $W_{0}$ affects $D_{0}$. During industrial pressing, the volume of the press matrices $\left(X_{0}, h_{0}\right)$ is kept constant, so that the variations in $D_{0}$ will modify the amount of feed powder $\left(m_{0}\right)$ and the mass of the green pressed and sintered tile. $P_{1}$ does not affect the tile mass during the manufacturing process.

In Figure 11, it can be observed that $m_{0}$ and the dried tile mass $\left(m_{3}\right)$ are lower due to the higher $W_{0}$ and consequent lower $D_{0}$, caused by the reduced flowability of the powder. This effect is more pronounced for higher moistures, especially for $m_{0}$, since the variation in bed density is summed up with the water loss after drying. A change in $\pm 0.5 \%$ in moisture content, which is usual in industrial practice, will cause a variation of $\pm 0.5 \%$ in $m_{0}$, considering the range of operation moistures to be usually employed (5-7\%).

(2) Influence of Powder Moisture and Pressing Pressure on Tile Dimensions. $W_{0}$ and $P_{1}$ will affect the size of the wet tile after pressing $\left(X_{2}\right)$, the size of the dried tile $\left(X_{3}\right)$, and the size of the sintered tile $\left(X_{4}\right)$, since $X_{1}=X_{0}$. Moreover, considering that $X_{2} \simeq X_{3}$, the influence of $W_{0}$ and $P_{1}$ on those values is practically the same. In Figure 12, the variation of $X_{2}$ and $X_{4}$ is presented as a function of $W_{0}$ for 3 different $P_{1}$. For a certain moisture and pressure, the wet tile size is larger than the sintered tile size due to the higher shrinkage (7-8\%) compared

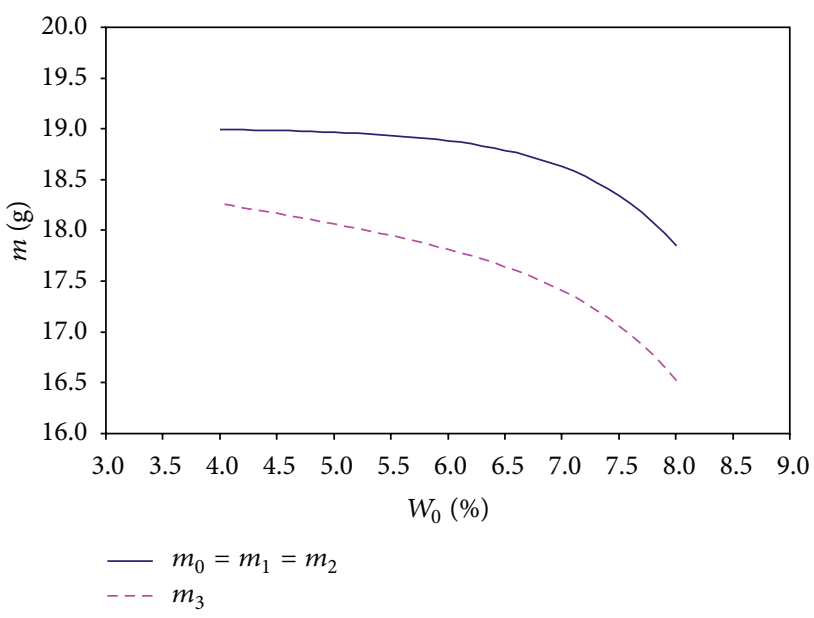

FIGURE 11: Influence of spray-dried powder moisture $\left(W_{0}\right)$ on the fill mass $\left(m_{0}\right)$ and tile masses $\left(m_{1}, m_{2}\right.$, and $\left.m_{3}\right)$.

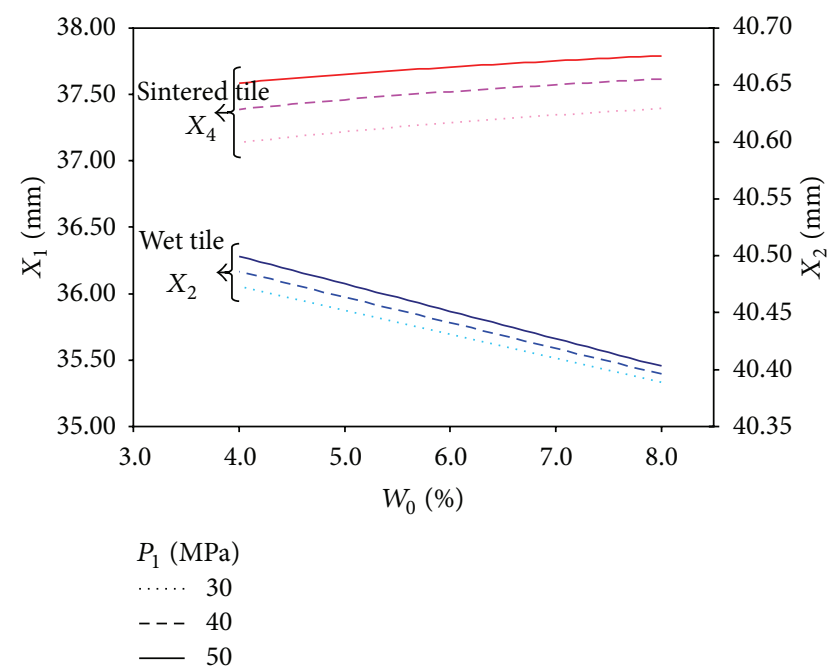

FIGURE 12: Influence of spray-dried powder moisture $\left(W_{0}\right)$ and maximum pressing pressure $\left(P_{1}\right)$ on wet and sintered tile sizes $\left(X_{2}\right.$ and $\left.X_{4}\right)$.

to the springback $(1-1.5 \%)$. The influence of $W_{0}$ is much larger on $X_{4}$ than on $X_{2}$, being in both cases a practically linear dependency, in the range of studied powder moisture. The effect of $W_{0}$ is opposite when wet and sintered tiles are compared: for higher moisture $X_{2}$ is diminished, while $X_{4}$ is augmented. In wet bodies, water works as a binder of particles, reducing the elastic response after pressing (lowering the springback) and enhancing $D_{3}$. When $S_{2}$ is reduced, the wet bodies present a lower size. When $D_{3}$ is increased, the bodies present a lower initial porosity, so that sintering shrinkage is lower, and the final dimensions of tiles are higher. 


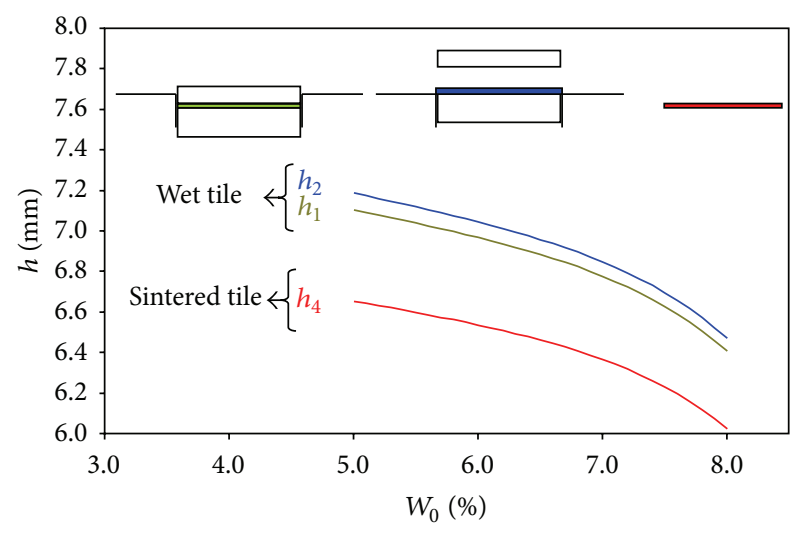

Figure 13: Influence of the powder moisture $\left(W_{0}\right)$ on the tile thickness $(h)$ along the fabrication steps, for a maximum pressure of $40 \mathrm{MPa}$.

The effect of $P_{1}$ is similarly much higher on the sintered tiles when compared to the wet tiles. Nevertheless, the influence is directly proportional in both cases, for wet and sintered tiles, in contrast to the effect of $W_{0}$.

(3) Influence of Powder Moisture and Pressing Pressure on Tile Thickness. In Figure 13, the variation of $h_{1}, h_{2}$, and $h_{4}$ as a function of $W_{0}$ is shown for a $P_{1}$ of $40 \mathrm{MPa}$.

As mentioned before, for this particular composition $h_{2} \cong$ $h_{3}$, so that the effect of $W_{0}$ and $P_{1}$ will be similar. For higher $W_{0}$, the tile thickness is reduced, being this effect similar for $h_{1}, h_{2}$, and $h_{4}$, since the curves present the same trend. This behaviour is markedly different from the one observed for the size (Figure 12). The variation of the thickness of tiles with $W_{0}$ seems to depend to a greater extent on the mass variations of the powder fed to the matrix during filling. Indeed, the trends of curves in Figures 13 and 11 are comparable. This indicates that $m_{0}$ into the press matrix has a larger effect on $h$ than $S_{2}$ and $S_{4}$, explaining the behaviour observed in Figure 13.

Figure 14 shows the variation of $h$ as a function of $W_{0}$ for 3 different $P_{1}(30,40$, and $50 \mathrm{MPa})$. For convenience, only the results for $h_{2}$ and $h_{4}$ are presented, since $h_{1}$ values are similar to those of $h_{2}$.

For a certain $W_{0}$, when $P_{1}$ is increased, the tile thickness is reduced, both for a wet body $\left(h_{2}\right)$ and for a sintered body $\left(h_{4}\right)$. The effect of pressure is decreased for higher pressure values, since the particles are closer. The influence of pressure on the thickness is higher for the wet body than for the sintered body, since the curves are closer in this case when compared to the curves of the wet body.

\section{Conclusions}

Empirical equations were obtained correlating the dependent properties to independent variables for fixed raw materials composition and processing conditions.

It was observed that $S_{2}, S_{3}$, and $S_{4}$ presented different orders of magnitude, suggesting that the contribution of $S_{3}$ to the dimensional change is not significant under the studied experimental conditions. The correlations were chosen by the lowest deviation standard value, implying minimal lack of fit

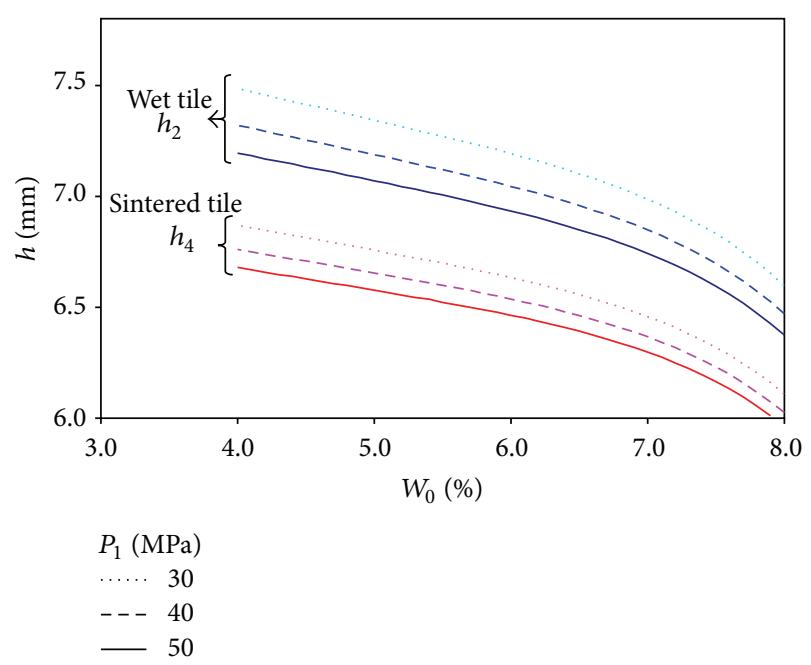

FIGURE 14: Influence of powder moisture $\left(W_{0}\right)$ and pressing pressure $\left(P_{1}\right)$ on tile thickness $(h)$.

and experimental errors. In all cases, the residuals could be considered randomly distributed around a zero mean value, corresponding to a common constant variance and normal distribution.

On the basis of the statistical analysis, the regression equations obtained were accepted to describe the effect of

(i) powder moisture content $\left(W_{0}\right)$ on fill density $\left(D_{0}\right)$,

(ii) powder moisture content $\left(W_{0}\right)$ and compaction pressure $\left(P_{1}\right)$ on springback $\left(S_{2}\right)$,

(iii) powder moisture content $\left(W_{0}\right)$ and compaction pressure $\left(P_{1}\right)$ on dry bulk density $\left(D_{3}\right)$,

(iv) maximum firing temperature $\left(T_{4}\right)$ and dry bulk density $\left(D_{3}\right)$ on firing shrinkage $\left(S_{4}\right)$.

A computational model that permits predicting the intermediate variables of ceramic tiles during their processing (mass, dry bulk density, size, and thickness) and their final dimensions' properties (size and thickness) was obtained. The multivariable model found makes use of both material balance equations and correlated equations. The used methodology proved to be a useful tool for planning and analysing experiments to find the influence of the mean press operational conditions on the variables of the empirical relationships needed to complete the calculation model. The analysis of the data obtained shows that

(i) when the powder moisture $\left(W_{0}\right)$ is increased, the amount of powder fed into the press $\left(m_{0}\right)$ is decreased. The same effect, with a higher intensity, is also observed for the dried mass of compacted tiles $\left(m_{3}\right)$;

(ii) the sizes of green bodies $\left(X_{2}\right.$ and $\left.X_{3}\right)$ are slightly reduced when the powder moisture $\left(W_{0}\right)$ is increased, and they augment for higher pressing pressure $\left(P_{1}\right)$ as a result of the springback $\left(S_{2}\right)$;

(iii) the final tile size $\left(X_{4}\right)$ is larger for higher powder moisture contents $\left(W_{0}\right)$ and the pressing pressure values $\left(P_{1}\right)$ due to the increase of density $\left(D_{3}\right)$. 
The effect of both variables on $X_{4}$ is higher than that on $X_{2}$ and $X_{3}$;

(iv) the thickness of both green $\left(h_{1}, h_{2}\right.$, and $\left.h_{3}\right)$ and sintered tiles $\left(h_{4}\right)$ decreases for lower powder moisture $\left(W_{0}\right)$ and pressing pressure $\left(P_{1}\right)$.

For the operational conditions considered, the regression equations represent the behaviour of the studied variables at lab scale within a high confidence level. Therefore, before using them to evaluate different press control conditions and strategies, their efficiency should be verified to reproduce industrial data. This is going to be accomplished in a further work, including a computational model to be established according to pressing operational conditions and control strategies in industrial scale. The aim is that the variables of the final product, particularly the tile thickness and size, are kept within a specific quality range.

\section{Acknowledgments}

Capes (Coordenação Geral de Aperfeiçoamento de Pessoal de Nível Superior, Brazil), DGU (Dirección General de Universidades, Spain), ERDF (European Regional Development Found), and IMPIVA (Instituto de la Mediana y Pequeña Industria Valenciana, Spain) are acknowledged for financial support as well the Spanish producer of ceramic tiles ROCERSA (Roig Cerámica S. A.) for providing raw materials.

\section{References}

[1] A. Azadeh, M. Moghaddam, P. Geranmayeh, and A. Naghavi, "A flexible artificial neural network-fuzzy simulation algorithm for scheduling a flow shop with multiple processors," International Journal of Advanced Manufacturing Technology, vol. 50, no. 5-8, pp. 699-715, 2010.

[2] J. A. Heredia and M. Gras, "Empirical procedure for modeling the variation transmission in a manufacturing process," Quality Engineering, vol. 22, no. 3, pp. 150-156, 2010.

[3] J. A. Heredia and M. Gras, "Statistical estimation of variation transmission model in a manufacturing process," International Journal of Advanced Manufacturing Technology, vol. 52, no. 5-8, pp. 789-795, 2011.

[4] T. F. Edgar, "Control of unconventional processes," Journal of Process Control, vol. 6, no. 2-3, pp. 99-110, 1996.

[5] G. Mallol, "Control y automatización en la industria cerámica: evolución y perspectivas," in $9^{\circ}$ Congreso Mundial de la Calidad del Azulejo y del Pavimento Cerámico (Qualicer '06), pp. 47-72, Castellón, Spain, 2006.

[6] ASCER, Guía de la Baldosa Cerámica, Instituto Valenciano de la Edificación, Castellón, Spain, 2006.

[7] ISO13006, "Ceramic tiles-definitions, classification, characteristics and marking," 1998.

[8] E. Sánchez, J. García-Ten, V. Sanz, and A. Moreno, "Porcelain tile: almost 30 years of steady scientific-technological evolution," Cerâmics International, vol. 36, no. 3, pp. 831-845, 2010.

[9] A. de Noni Jr., D. Hotza, V. C. Soler, and E. S. Vilches, "Influence of composition on mechanical behaviour of porcelain tile-part I: microstructural characterization and developed phases after firing," Materials Science and Engineering A, vol. 527, no. 7-8, pp. 1730-1735, 2010

[10] J. L. Amorós, A. Blasco, J. E. Enrique, and A. Escardino, "Estudio de la compactación de soportes cerámicos (bizcochos) de pavimento y revestimiento-I: influencia del tamaño de gránulo de atomizado," Boletín de la Sociedad Española de Cerámica y Vidrio, vol. 21, no. 4-5, pp. 245-250, 1982.

[11] J. L. Amorós, V. Beltrán, F. Negre, and A. Escardino, "Estudio de la compactación de soportes cerámicos (bizcochos) de pavimento y revestimiento-II: influencia de la presión y humedad de prensado," Boletín de la Sociedad Española de Cerámica y Vidrio, vol. 22, no. 1, pp. 8-18, 1983.

[12] J. L. Amorós, A. Escardino, V. Beltrán, and J. E. Enrique, "Quality control in tile production," Interceram, vol. 33 , no. 2, pp. 50$54,1984$.

[13] J. L. AmorósJL, A. Escardino, E. Sánchez, and F. Zaera, "Stabilità delle dimensioni nelle piastrelle porose monocotte," Cerám Información, vol. 324, pp. 56-67, 1993.

[14] J. L. Amorós, G. Mallol, A. Mezquita et al., "Melhoria da estabilidade dimensional de peças de grés porcelânico através da medida contínua da umidade dos suportes prensados," Cerâmics International, vol. 9, no. 2, pp. 6-15, 2004.

[15] A. de Noni Jr., C. Modesto, A. P. N. de Oliveira, and D. Hotza, "Dimensional modeling and control of ceramic tile," American Ceramic Society Bulletin, vol. 85, no. 11, pp. 9201-9207, 2006.

[16] J. L. Amorós, Pastas cerámicas para pavimentos de monococción-influencia de las variables de prensado sobre las propiedades de la pieza en crudo y sobre su comportamiento durante el prensado y la cocción [Ph.D. thesis], Universitat Jaume I, Castellón, Spain, 1987.

[17] A. Escardino, J. L. Amorós, and J. E. Enrique, "El diagrama de gresificación en la fabricación de pavimentos de gres," Cerám Información, vol. 84, pp. 211-220, 1981.

[18] J. L. Amorós, A. Escardino, V. Beltrán, and J. E. Enrique, “Control de la compactación durante el proceso de fabricación de pavimentos y revestimientos cerámicos," Técnica Cerámica, vol. 118, pp. 1307-1314, 1983.

[19] J. L. Amorós, A. Blasco, J. E. Enrique, and F. Negre, "Características de polvos cerámicos para prensado," Boletín de la Sociedad Española de Cerámica y Vidrio, vol. 26, no. 1, pp. 31-37, 1987.

[20] C. Coelho, C. A. Scopel, N. Roqueiro, and D. Hotza, "Quantitative mineralogical analysis of ceramic raw materials: an alternative approach," Journal of Materials Science Letters, vol. 20, no. 11, pp. 1041-1042, 2001.

[21] D. C. Montgomery, Design and Analysis of Experiments, John Wiley \& Sons, New York, NY, USA, 5th edition, 2001.

[22] O. L. Davies, Métodos Estadísticos Aplicados a la Investigación y a la Producción con Especial Referencia a la Industria Química, Aguilar, Madrid, Spain, 2nd edition, 1965.

[23] J. C. Reed, Introduction to the Principles of Ceramics Processing, Wiley Interscience, New York, NY, USA, 2nd edition, 1993.

[24] D. Santos-Barbosa, B. Vicente, D. Hotza, and R. A. F. Machado, "Análisis de los parámetros de proceso sobre la media y la variabilidad de la densidad aparente pos secado de revestimientos cerámicos," in $11^{\circ}$ Congreso Mundial de la Calidad del Azulejo y del Pavimento Cerámico (Qualicer '10 ), Castellón, Spain, 2010.

[25] J. L. Amorós, A. Blasco, J. E. Enrique, V. Beltrán, and A. Escardino, "Variables en la compactación de soportes cerámicos de pavimento y revestimiento," Técnica Cerámica, vol. 105, pp. 792-812, 1982. 
[26] J. L. Amorós, A. Moreno, M. J. Orts, and A. Escardino, "La operación de prensado en la fabricación de pavimentos por monococción-II: influencia de la naturaleza del polvo de prensas sobre las propiedades de las piezas en cocido," Boletín de la Sociedad Española de Cerámica y Vidrio, vol. 29, no. 3, pp. 151158, 1990.

[27] V. Bagán, Efecto de las condiciones de operación en las diferentes etapas del proceso sobre las propiedades y características de un pavimento de muy baja porosidad [Ph.D. thesis], Universitat Jaume I, Castellón, Spain, 1991.

[28] M. J. Orts, Sinterización de piezas de pavimento gresificado [Ph.D. thesis], Universitat Jaume I, Castellón, Spain, 1991. 

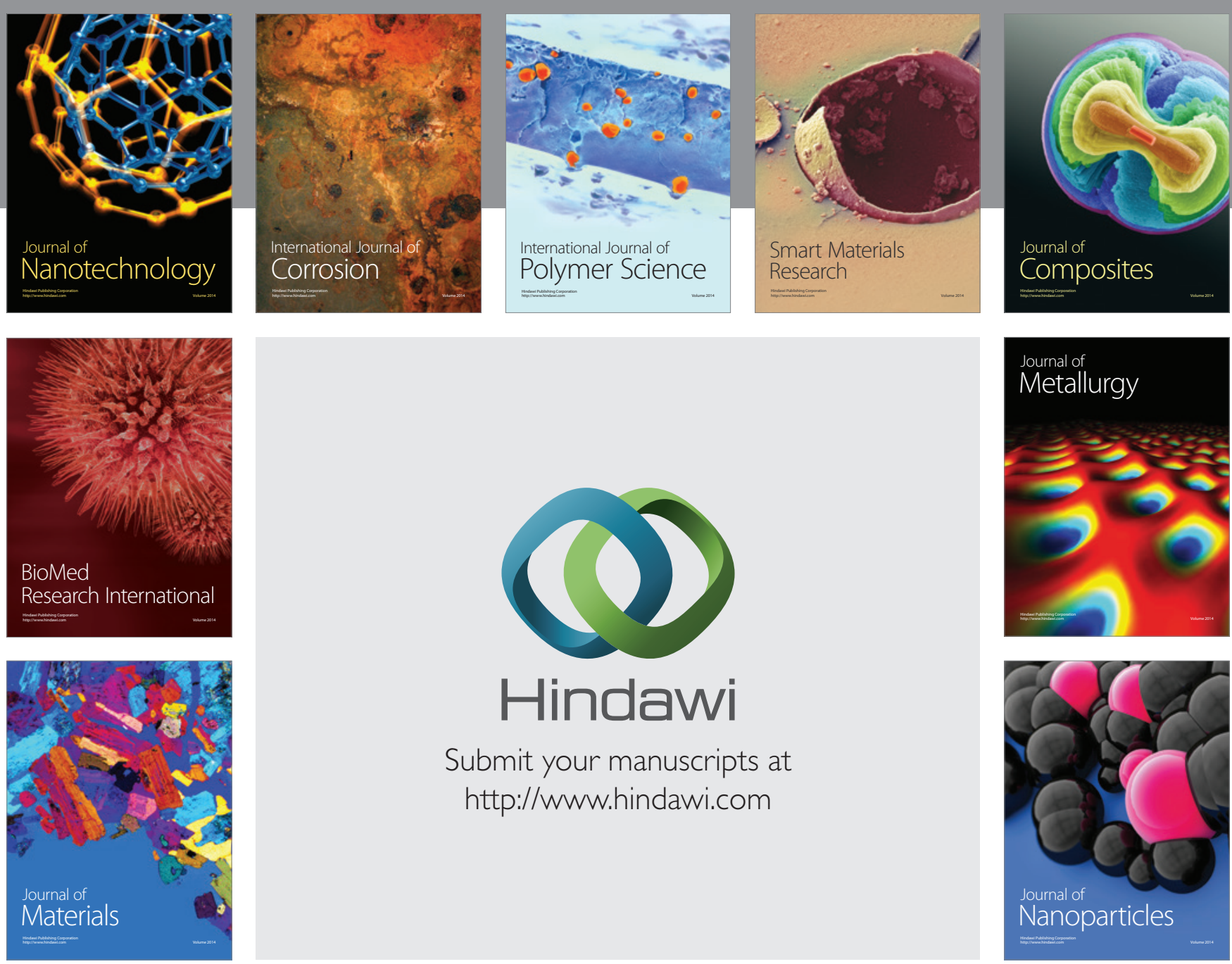

Submit your manuscripts at http://www.hindawi.com
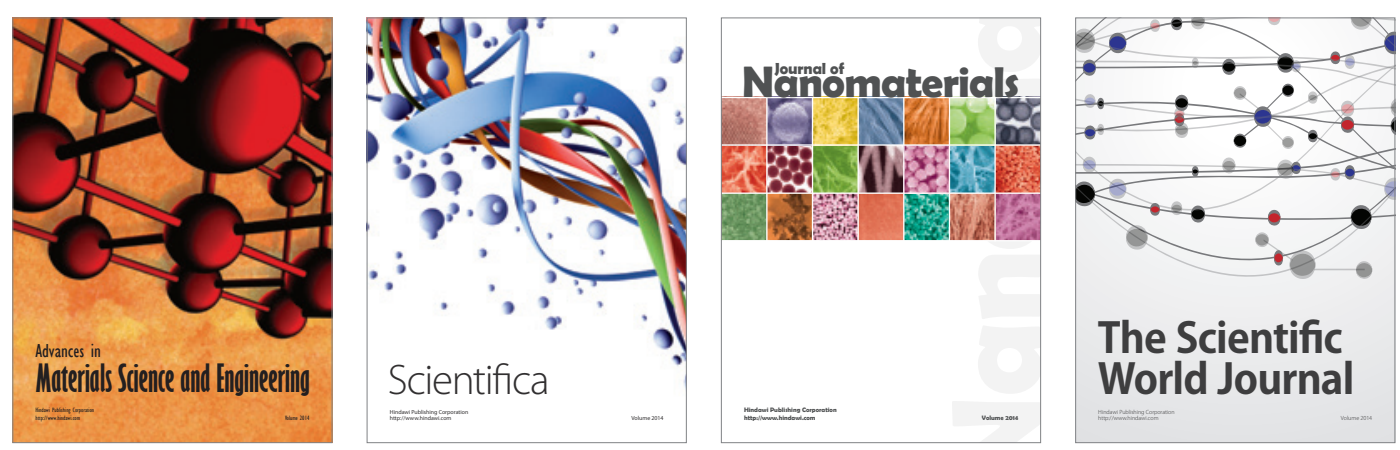

\section{The Scientific World Journal}
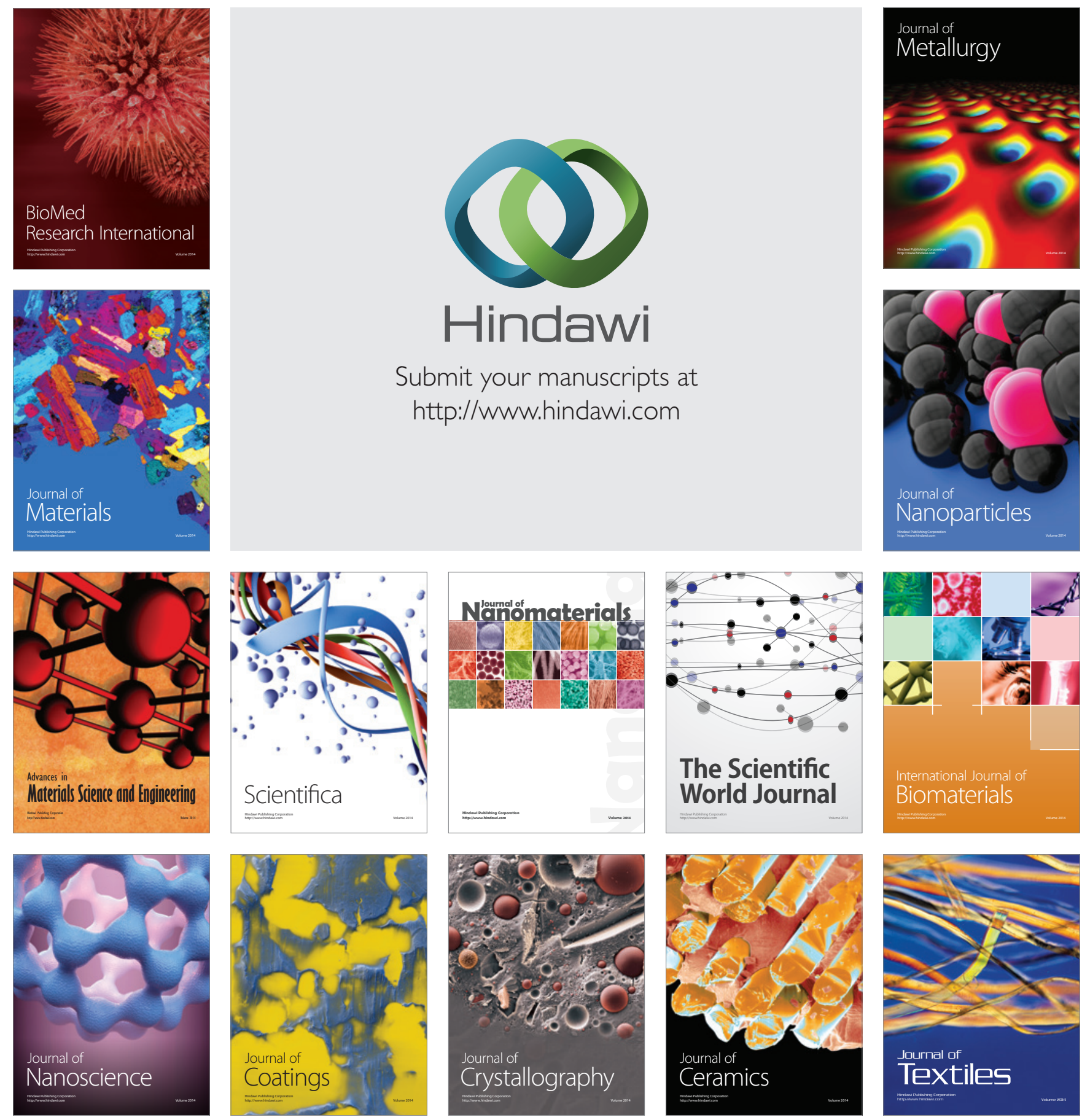